\title{
BMJ Open Postural sway, working years and BMI in healthy truck drivers: an observational study
}

\author{
Daniela Ohlendorf, ${ }^{1}$ Paul Troebs, ${ }^{1}$ Andreas Lenk, ${ }^{1}$ Eileen Wanke, ${ }^{1}$ Jörg Natrup, ${ }^{2}$ \\ David Groneberg ${ }^{1}$
}

To cite: Ohlendorf $D$, Troebs $P$, Lenk $A$, et al. Postural sway, working years and $\mathrm{BMI}$ in healthy truck drivers: an observational study. BMJ Open 2017;7:e013281. doi:10.1136/ bmjopen-2016-013281

- Prepublication history and additional material are available. To view these files please visit the journal online (http://dx.doi.org/ 10.1136/ bmjopen-2016-013281).

Received 4 July 2016 Revised 13 February 2017 Accepted 8 March 2017



${ }^{1}$ Institute of Occupational Medicine, Social Medicine and Environmental Medicine, Goethe-University Frankfurt/ Main, Frankfurt, Germany ${ }^{2}$ Society for Biomechanics Münster mH (GBiM), Münster, Germany

Correspondence to Daniela Ohlendorf; ohlendorf@ med.uni-frankfurt.de

\section{ABSTRACT}

Objectives The following study analyses the influence of risk factors among the occupational group of truck drivers on postural control and body mass index (BMI).

Design Observational study.

Setting One motorway station close to several highways in Germany.

Participants 180 truck drivers (177 male/3 female), aged 21-65 years old, took part in this study.

Outcome measures Postural control was examined using a pressure plate. In order to examine the influence of body weight (BMI) and working years on postural control, subjects were divided into samples of five and three groups, respectively. Furthermore, it was evaluated whether the subjects suffered from back pain. For data analysis, the Kruskal-Wallis test was used as the data were not normally distributed. Once the $p$ value of the Kruskal-Wallis test was $p \leq 0.05$, the Conover-Iman comparison and afterwards the Bonferroni-Holm correction were used. The significance level was set at $\alpha \leq 0.05$. Results Regarding the number of working years, a significant increase of frontal $(p \leq 0.04)$ and sagittal $(p \leq 0.001)$ sway were observed. The correlation of the five BMI groups with the number of working years demonstrates that an increase of the working years leads to an increase of BMI $(p \leq 0.03)$. Furthermore, the majority of truck drivers participating in this study suffered from back pain (61.7\%).

Conclusions BMI and musculoskeletal impairment are indicators of health risk factors. In this study, it is shown that an increasing number of working years and an increasing BMI lead to a decrease in frontal and sagittal postural sway. In addition, the number of working years correlates with body weight and back pain.

\section{INTRODUCTION}

Human posture and stability are influenced and controlled by a large number of endogenous systems of the body to keep up its stability. ${ }^{1}$ All biological systems permanently try to minimise energetic costs by maintaining an upright posture. One of these systems is the muscular-skeletal system. The body weight is evenly distributed on both feet with the least muscular activity and the centre of mass is placed over the centre of pressure (COP). Equal distribution of body weight minimises
Strengths and limitations of this study

One strength of this study is the large number of participants.

- Another is the separate analysis according to body mass index, working years and back pain.

- One limitation of the study is the measuring of the postural control outside the driver's cabin.

- Furthermore, external influences such as the specification seats classification and the seat cushioning were not taken into account.

skeletal pressure..$^{2-6}$ If this system is impaired, disturbed gait patterns and an increased risk of falling are observed, for example, in patients with Parkinson's disease or cerebral palsy. ${ }^{78}$ Measuring COP or gait patterns in people with Parkinson's disease or cerebral palsy has been used as an early indicator for musculoskeletal dysfunction.

Furthermore, there are neuronal systems like the visual and vestibular system which interact with each other. ${ }^{9}$ This way a finely tuned system is formed, which is capable of stabilising the posture during all movement tasks. If necessary, counter-regulatory actions might be taken.

Human posture is influenced by biomechanical data of the proprioceptors and by environmental factors. ${ }^{10}$ However, the physiological postural balance can be disturbed by means of several external influences and may lead to a non-physiological foot pressure and an increased pressure on the rearfoot and midfoot. ${ }^{11}$ The most important causes are obesity and lack of exercise. ${ }^{11} 12$ Birtane et $a l^{11}$ assumed that obesity leads to a shift of the body's centre of gravity resulting in an excessive loading of some parts of the foot, especially the rearfoot and midfoot. This dysfunctional loading of the feet influences the compensation mechanisms of postural control so that back muscles, on spinal and neuronal level, eyes and the vestibular system have to compensate accordingly. 
There are several studies comparing the range of body sway between normal weight subjects and overweight subjects. Colné $e t a l^{13}$ states that there is an increase of mediolateral sway within the group of overweight subjects compared with the body sway within the group of normal weight subjects. In addition, Hue $e t a l^{14}$ have shown that increasing obesity correlates with a shift of the body's centre of gravity towards the frontal direction. This shift directly influences the postural control and foot loading. Changes in postural control with increasing age have been found by Røgind et al..$^{15}$

Postural control is also influenced by monotonous sitting over a long period of time. Szeto $e a^{16}$ examined this with a group of bureau employees and concluded that people who spend a lot of time sitting in front of a computer or a desk more often suffer from back pain.

Merely $20 \%$ of truck drivers interviewed by Ellinghaus and Steinbrecher ${ }^{17}$ did not have any physical discomfort at all while driving. About $60 \%$ complained of occasional or frequent back pain, muscle pain and/or joint pain. With increasing age, a growth of these disorders could be observed. ${ }^{17}$ Gawda et $a l^{18}$ observed an increase of frontal and sagittal sway as an effect of back pain.

Truck drivers are an occupational group evidentially suffering from obesity, back pain and a lack of exercise while spending a lot of hours in a sitting position. ${ }^{19-21}$

Due to their profession they spend most of the working time sitting in a forced position in their trucks. In addition, they normally have less time for exercise or regular sport activities beside their job. Moreover, truck drivers are mostly used to an unhealthy and fatty diet ${ }^{22}$ as a consequence of which obesity is a common disease among truck drivers. ${ }^{21}$ 23-25

The fact that truck driving can cause damage to health has already been shown in several studies.

A number of risk factors, such as overweight or rather obesity, long periods of sitting and lack of exercise are often found in truck drivers. These factors may damage the musculoskeletal system and result in both back pain and/or impaired compensational movements. These may be quantified by measuring body posture or postural sway.

Therefore, this study examines the effects of obesity, long monotonous working conditions in a forced position and back pain in the professional group of truck drivers on the postural sway. The working hypotheses of this study are as follows:

1. A rising number of working years leads to declining postural sway by increased frontal and sagittal sway.

2. Obesity is an independent factor for declining postural sway in truck drivers.

3. Participants reporting back pain also have deviating postural sway and weight distribution.

\section{METHODS}

Subjects

One hundred and eighty healthy, randomly chosen truck drivers (177 male/3 female) took part in this study, age
BMI distribution

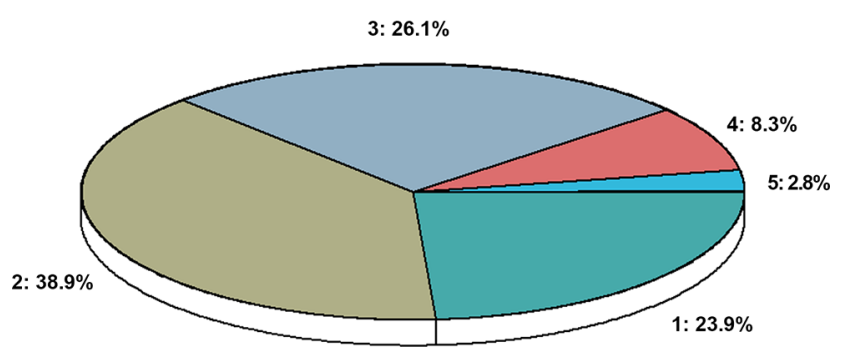

Figure 1 BMI distribution: 1 (normal weight) BMI 18.5$24 \mathrm{~kg} / \mathrm{m}^{2}, 2$ (pre-obesity) BMI 25-29.9 kg/m², 3 (obesity ${ }^{\circ}$ ) BMI 30-34.9 kg/m², 4 (obesity II ${ }^{\circ}$ BMI 35-39.9kg/m², 5 (obesity $\mathrm{III}^{\circ}$ ) BMl $>40 \mathrm{~kg} / \mathrm{m}^{2}$ ). BMI, body mass index.

ranging from 21 to 65 years (average age $46.5 \pm 10.65$ years). Participants had up to 45 years of work experience and worked an average of 11 hours daily. The average BMI of the subjects was $29.1 \pm 5.6 \mathrm{~kg} / \mathrm{m}^{2}$.

Only healthy individuals without any diseases in need of treatment such as acute infections were considered to participate in this study.

Subjects were divided into three groups with almost the same sample size based on the number of working years (group 1: working experience of up to 12 years, group 2: working experience between 13 and 25 years and group 3: working experience $>25$ years.

Subjects were also grouped according to the BMI classification of the $\mathrm{WHO}^{26}$ : group 1 (normal weight), group 2 (pre-obese), group 3 (obesity ${ }^{\circ} 1$ ), group 4 (obesity ${ }^{\circ} 2$ ) and group 5 (obesity ${ }^{\circ}$ ) (figure 1 ).

Furthermore, subjects had to complete a questionnaire (see online supplementary file 1) in order to differentiate between individuals with and without back pain. In addition, the occurrence of back pain (daily, weekly, monthly, never) was evaluated. Finally, subjects had to declare whether the back pain was being treated by a doctor.

This study was approved by the ethics research committee involving human subjects of the Goethe-University (134/14) in Frankfurt am Main, Germany.

\section{Measurement system}

For pressure measurement, the GP Multisens plate (GeBioM, Münster, Germany) was used. The measurement plate is $45 \mathrm{~cm} \times 55 \mathrm{~cm}$ large with a measuring surface of $38.5 \mathrm{~cm} \times 38.5 \mathrm{~cm}$ on which 2304 resistance sensors are installed $\left(1.25\right.$ sensors per $\left.\mathrm{cm}^{2}\right)$. The sampling is $200 \mathrm{~Hz}$

Table 1 Mean values and SD of age, height, weight and $\mathrm{BMI}$ grouped by working years

\begin{tabular}{lllll}
\hline $\begin{array}{l}\text { Working } \\
\text { years }\end{array}$ & $\begin{array}{l}\text { Mean age } \\
\text { (years) }\end{array}$ & $\begin{array}{l}\text { Mean } \\
\text { height } \\
\mathbf{( c m )}\end{array}$ & $\begin{array}{l}\text { Mean } \\
\text { weight } \mathbf{( k g )}\end{array}$ & $\begin{array}{l}\text { Mean BMI } \\
\left(\mathbf{k g} / \mathbf{m}^{2}\right)\end{array}$ \\
\hline Group 1 & $34.7 \pm 9.0$ & $179 \pm 7.5$ & $91.3 \pm 22.9$ & $28.3 \pm 6.0$ \\
Group 2 & $46.35 \pm 7.1$ & $178 \pm 6.4$ & $91.15 \pm 21.1$ & $28.64 \pm 5.9$ \\
Group 3 & $55.8 \pm 4.3$ & $179.2 \pm 6.9$ & $97.6 \pm 16.2$ & $30.4 \pm 4.8$ \\
\hline
\end{tabular}

BMI, body mass index. 
Table 2 Mean values and SD of age, height, weight and BMI grouped by BMI

\begin{tabular}{lllll}
\hline $\begin{array}{l}\text { BMI } \\
\text { groups }\end{array}$ & $\begin{array}{l}\text { Mean age } \\
\text { (years) }\end{array}$ & $\begin{array}{l}\text { Mean } \\
\text { height }(\mathbf{c m})\end{array}$ & $\begin{array}{l}\text { Mean weight } \\
(\mathbf{k g})\end{array}$ & $\begin{array}{l}\text { Mean BMI } \\
\left(\mathbf{k g} / \mathbf{m}^{2}\right)\end{array}$ \\
\hline I & $42.8 \pm 4.0$ & $176.7 \pm 7.3$ & $72.1 \pm 8.5$ & $23.0 \pm 1.6$ \\
II & $47.7 \pm 10.6$ & $179.4 \pm 6.2$ & $88.8 \pm 7.5$ & $27.6 \pm 1.4$ \\
III & $47.9 \pm 9.0$ & $179.2 \pm 7.8$ & $104.9 \pm 11.2$ & $32.6 \pm 1.8$ \\
IV & $46.8 \pm 11.9$ & $179.0 \pm 5.3$ & $119.7 .7 \pm 7.7$ & $36.9 \pm 1.5$ \\
V & $48.4 \pm 13.3$ & $179.0 \pm 6.0$ & $155.0 \pm 27.3$ & $48.2 \pm 6.6$ \\
\hline
\end{tabular}

BMI, body mass index.

and the sensors work with a precision of $\pm 5 \%$. The pressure is measured in Pascal (force/area).

\section{Data collection}

First of all, the participants were weighed and their height was measured in order to calculate their BMI.

Afterwards the participants had to stand barefoot on the measuring surface of a pressure measurement plate. They were asked to maintain their habitual foot position. Each measurement of the postural sway took $30 \mathrm{~s}$. The mean value of five independent repetitions was calculated.

\section{Evaluation parameters}

The following parameters of postural sway were considered in this study: (1) maximal excursion of frontal (forward-backward) and sagittal (mediolateral) sway $(\mathrm{mm}),(2)$ percentage distribution of body weight on each foot section (forefoot left, forefoot right, rearfoot left, rearfoot right), (3) total percentage body weight distribution on forefoot and rearfoot, (4) percentage body weight distribution between left and right foot.

\section{Data analysis}

The recorded data were analysed with the BIAS software (V. 10.12, GeBioM, Münster, Germany). The assumption of normality was tested using the Kolmogorov-Smirnov-Lilliefors test. As the data were not normally distributed, the Kruskal-Wallis test was used for all group

\begin{tabular}{lcc}
\hline Table 3 & Evaluation parameters of postural sway \\
\hline & Median & $\begin{array}{l}\text { Percentile } \\
\text { (1st/3rd) }\end{array}$ \\
\hline Frontal sway (mm) & 9.4 & $6.4 / 13.2$ \\
\hline Sagittal sway (mm) & 16.4 & $12.6 / 20.5$ \\
\hline Forefoot left (\%) & 19.7 & $16.8 / 22.4$ \\
\hline Forefoot right (\%) & 20.8 & $17.7 / 23.8$ \\
\hline Rearfoot right (\%) & 31.2 & $27.4 / 36.4$ \\
\hline Rearfoot left & 27.3 & $24.1 / 30.8$ \\
\hline Left foot (\%) & 46.9 & $42.2 / 52.2$ \\
\hline Right foot (\%) & 53.0 & $47.8 / 57.8$ \\
\hline Forefoot (\%) & 40.9 & $36.1 / 44.4$ \\
\hline Rearfoot (\%) & 59.0 & $55.6 / 63.7$ \\
\hline
\end{tabular}

differences. If the $\mathrm{p}$ value of the Kruskal-Wallis test was $\mathrm{p} \leq 0.05$, the Conover-Iman comparison and afterwards the Bonferroni-Holm correction was used. The significance level was $\mathrm{p} \leq 0.05$.

\section{RESULTS}

The participating truck drivers were between 21 and 65 years of age (average age $46.5 \pm 10.65$ years). Their work experience ranged from 1 to 45 years (average work experience $21 \pm 11.65$ years) and they worked a mean 11 hours per day. The BMI of the subjects was on average $29.1 \pm 5.6 \mathrm{~kg} / \mathrm{m}^{2}$ (median $28.4 \mathrm{~kg} / \mathrm{m}^{2}$; min. $18.94 \mathrm{~kg} / \mathrm{m}^{2}$, $\left.\max .56 .74 \mathrm{~kg} / \mathrm{m}^{2}\right)$.

Subjects were divided into three groups according to their working years, so that subjects in group 1 with little experience have a mean work experience of $6.3 \pm 3.1$ years and a mean age of $34.7 \pm 9$ years. Subjects of group 2 show a mean work experience of $20 \pm 4.5$ years and a mean age of $46.3 \pm 7.1$ years. In group 3 (most experienced workers), there is a mean work experience of $34.35 \pm 4.3$ years with a mean age of $55.8 \pm 4.3$ years.

According to the group distribution of the BMI classification of the WHO,${ }^{26} 29.9 \%$ belong to group 1 (normal weight, BMI $18.5-24.9 \mathrm{~kg} / \mathrm{m}^{2}$ ) and $38.9 \%$ of the subjects to group 2 (pre-obese) with a BMI of $25-29.9 \mathrm{~kg} / \mathrm{m}^{2}$. Group 3 consists of $26.1 \%$ (obesity ${ }^{\circ} 1$, BMI $30-34.9 \mathrm{~kg}$ / $\mathrm{m}^{2}$ ) and group 4 of $8.3 \%$ (obesity ${ }^{\circ} 2$, BMI $35-39.9 \mathrm{~kg}$ / $\left.\mathrm{m}^{2}\right) .2 .8 \%$ have a BMI of $>40 \mathrm{~kg} / \mathrm{m}^{2}\left(\right.$ obesity $\left.{ }^{\circ} 3\right)$ and form group 5.

Table 1 includes mean values and SD of age, height, weight and BMI for the participants grouped by working years.

In table 2, the same parameters are illustrated for the participants according to BMI.

Table 3 shows the median and the percentiles (1st/3rd) of all parameters for all subjects. The median of frontal sway is $9.4 \mathrm{~mm}$, the first percentile $6.4 \mathrm{~mm}$ and the third percentile $13.2 \mathrm{~mm}$. The median of sagittal sway is $16.4 \mathrm{~mm}(12.6 \mathrm{~mm} / 0.5 \mathrm{~mm})$.

The median of percentage body weight distribution is highest on the right rearfoot with $31.2 \%(27.4 \% / 36.4 \%)$, while the median of the right forefoot has a percentage of $20.8 \%(17.7 \% / 23.8 \%)$. For the left foot, the following percentages for the median can be stated: the rearfoot has $27.3 \%(24.1 \% / 30.8 \%)$ and the forefoot has $19.7 \%$ $(16.8 \% / 22.4 \%)$. The comparison of the left and right side shows a higher percentage distribution on the right side with a median of $53.0 \%$ and percentiles of $47.8 \%$ and $57.8 \%$ (left foot: median $=47.0 \% ; 1 \mathrm{st}=42.2 \%$; $3 \mathrm{rd}=52.2 \%$ ). On average, the rearfoot is more loaded than the forefoot with $59.0 \%$ to $40.9 \%$ (rearfoot: $55.6 \% / 63.7 \%$; forefoot: $36.1 \% / 44.4 \%)$.

\section{Group comparison due to working years}

Table 3 shows the median and the percentiles (1st/3rd) of all parameters for all subjects. The median of frontal sway is $9.4 \mathrm{~mm}$, the first percentile $6.4 \mathrm{~mm}$ and the 


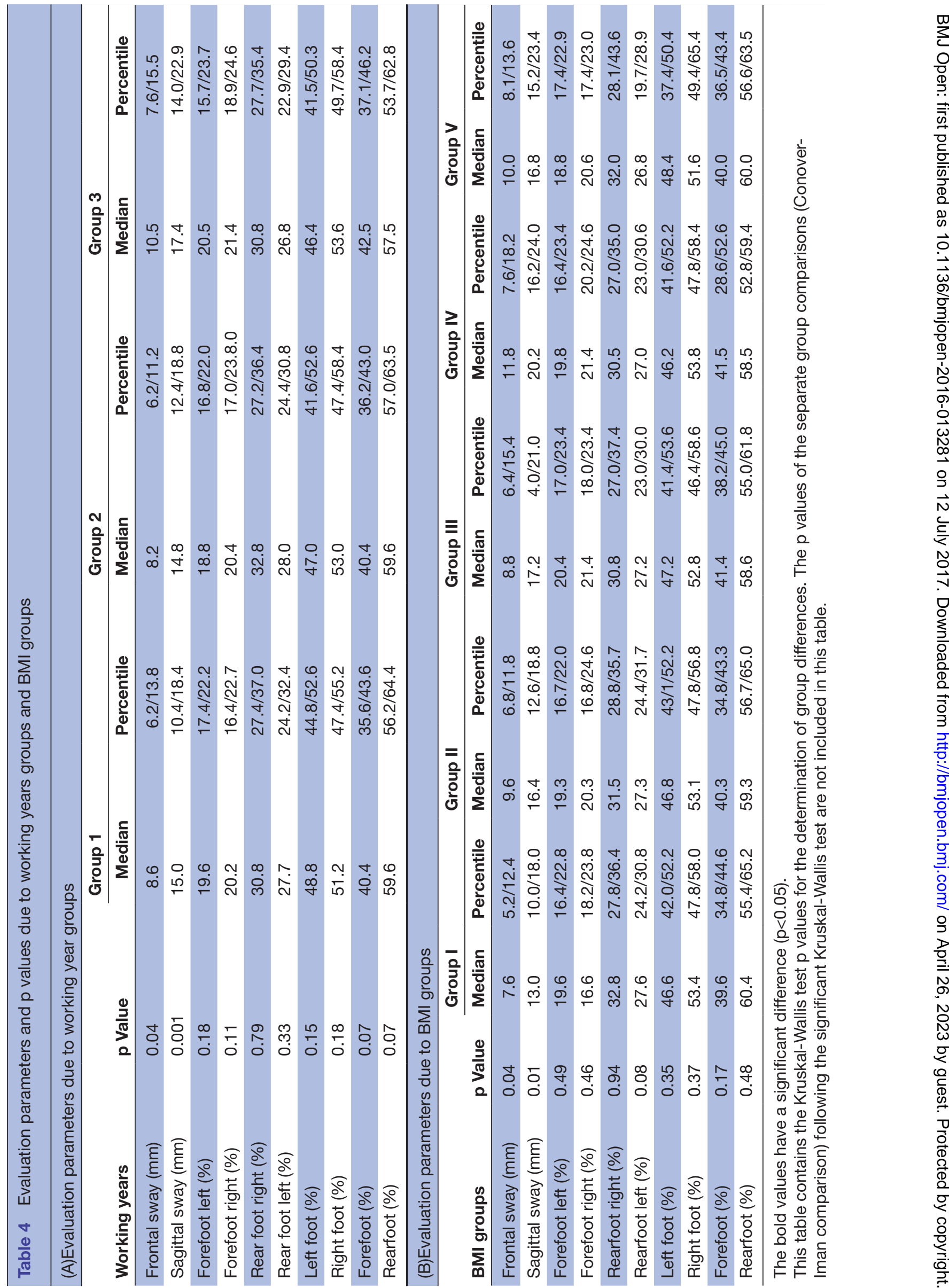




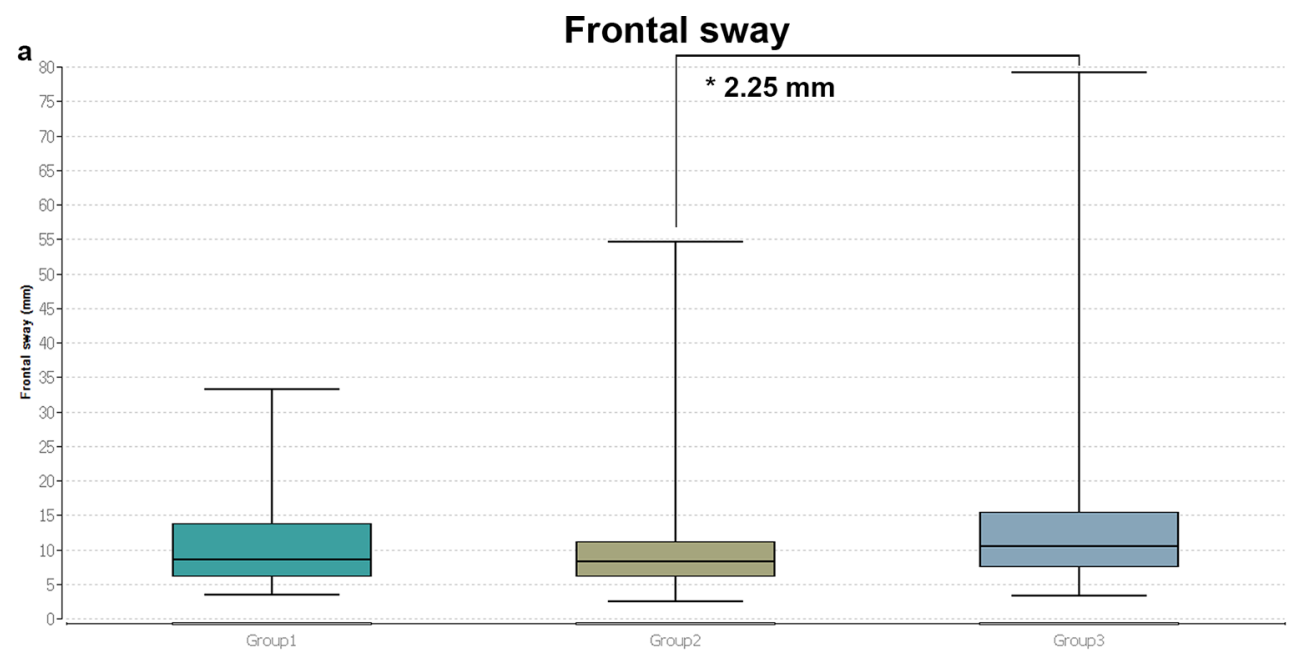

b

Sagittal sway

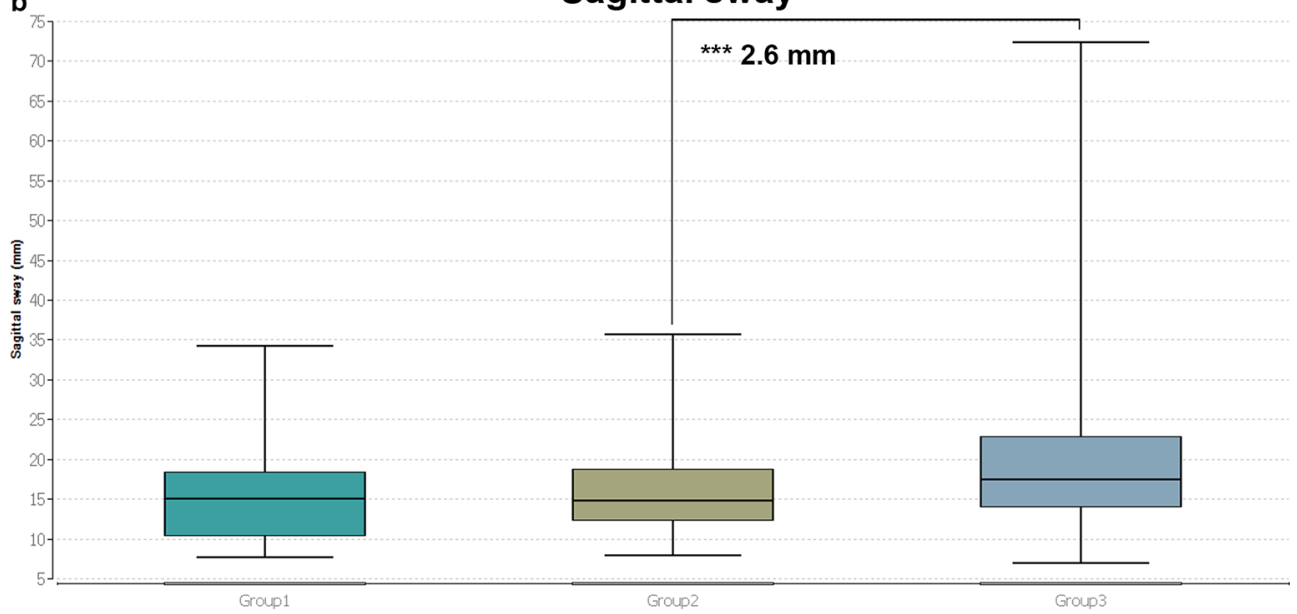

Figure 2 a and $\mathbf{b}$ Frontal and sagittal sway due to BMI. BMI, body mass index.

third percentile $13.2 \mathrm{~mm}$. The median of sagittal sway is $16.4 \mathrm{~mm}(12.6 \mathrm{~mm} / 20.5 \mathrm{~mm})$. The Kruskal-Wallis test finds significant differences for the frontal $(\mathrm{p}<0.04)$ and sagittal sway $(\mathrm{p}<0.001)$. The Conover-Iman comparison shows a significant difference between group 2 and 3 in regard to the frontal $(\mathrm{p}<0.01)$ and sagittal $(\mathrm{p}<0.001)$ sway. The median of the frontal sway indicates a smaller median in group $2(8.2 \mathrm{~mm})$ than in group $3(10.5 \mathrm{~mm})$. In the sagittal plane, there is a higher sway in group 3 than in group 2 (group 3: $17.4 \mathrm{~mm}$; group 2: $14.8 \mathrm{~mm}$ ) (table 4a; figure $2 \mathrm{a}, \mathrm{b})$. The percentage of load distribution shows no significant differences.

\section{Group comparison due to BMI}

Table 4 shows the $p$ values of the group comparison of the working years (postural sway). There are significant differences between the BMI groups as to the frontal $(\mathrm{p}<0.04)$ and sagittal $(\mathrm{p}<0.001)$ sway (table 4; figure 3a,b). In both parameters, a difference (Conover-Iman comparison; $\mathrm{p} \leq 0.01$ ) between groups 1 and 4 is observed, whereas a difference of the median is present with respect to the frontal fluctuation of $4.2 \mathrm{~mm}$ and in the sagittal fluctuation of
$7.0 \mathrm{~mm}$ (table $4 \mathrm{~b}$ ). No significant differences could be evaluated regarding the parameters of plantar pressure distribution.

\section{Working years group comparison due to BMI}

There is a significance of $p \leq 0.03$ due to the comparisons of the BMI of the three working year groups. The following Conover-Iman comparison reveals group differences $(p \leq 0.03)$ between groups 1 and 3 and between groups 2 and 3. In the first group, the median is $27.4 \mathrm{~kg} / \mathrm{m}^{2}$, in the second group $27.7 \mathrm{~kg} / \mathrm{m}^{2}$ and in the third group $30.0 \mathrm{~kg} /$ $\mathrm{m}^{2}$ (figure 4). This results in a median increase of BMI by approximately $2.6 \mathrm{~kg} / \mathrm{m}^{2}$ between the first and the third age group.

\section{Group comparison between subjects with and without back pain}

In total, $111(61.7 \%)$ out of 180 participants suffered from back pain. The Mann-Whitney U test plus Bonferroni-Holm correction found no significant differences between both groups (pack pain vs no back pain) with respect to all measured parameters. 
a

Frontal sway



b

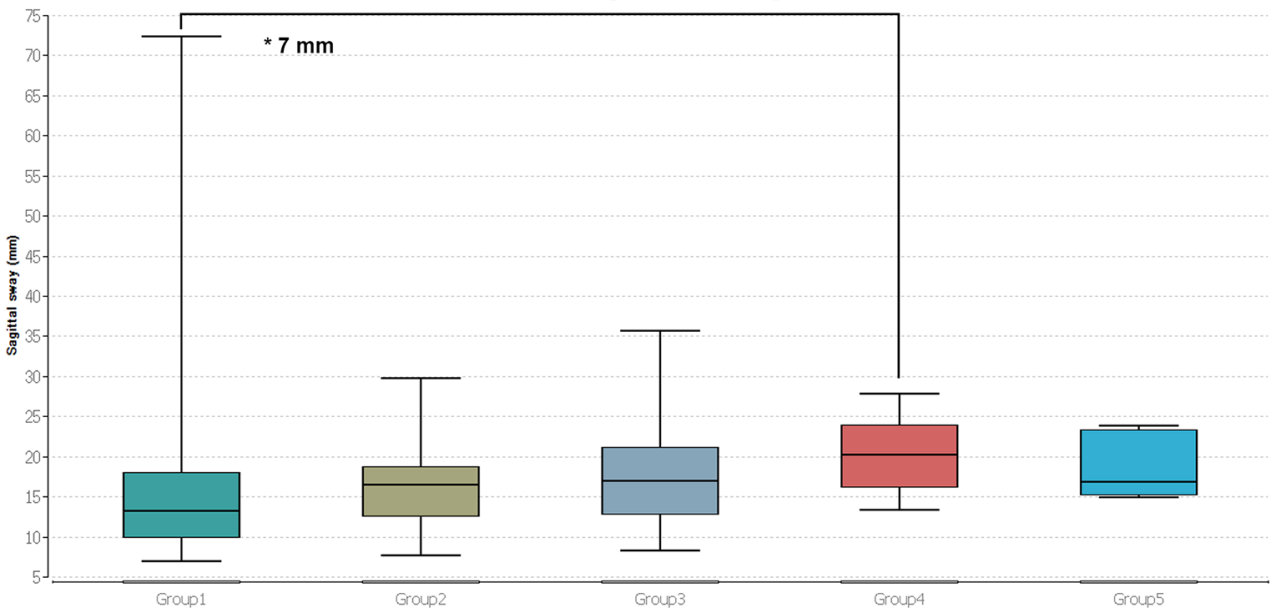

Figure 3a and b Frontal and sagittal sway in comparison of working years.

\section{DISCUSSION}

Truck drivers spend most hours of the day in a forced sitting position which probably contributes largely to their tendency to be overweight and to their suffering from back pain. The additional lack of exercise and an unhealthy diet may cause further damage to their health. Long sitting may impair the muscular-skeletal system resulting in back pain.

The present results confirm impaired postural sway in truck drivers. Since the working conditions cause

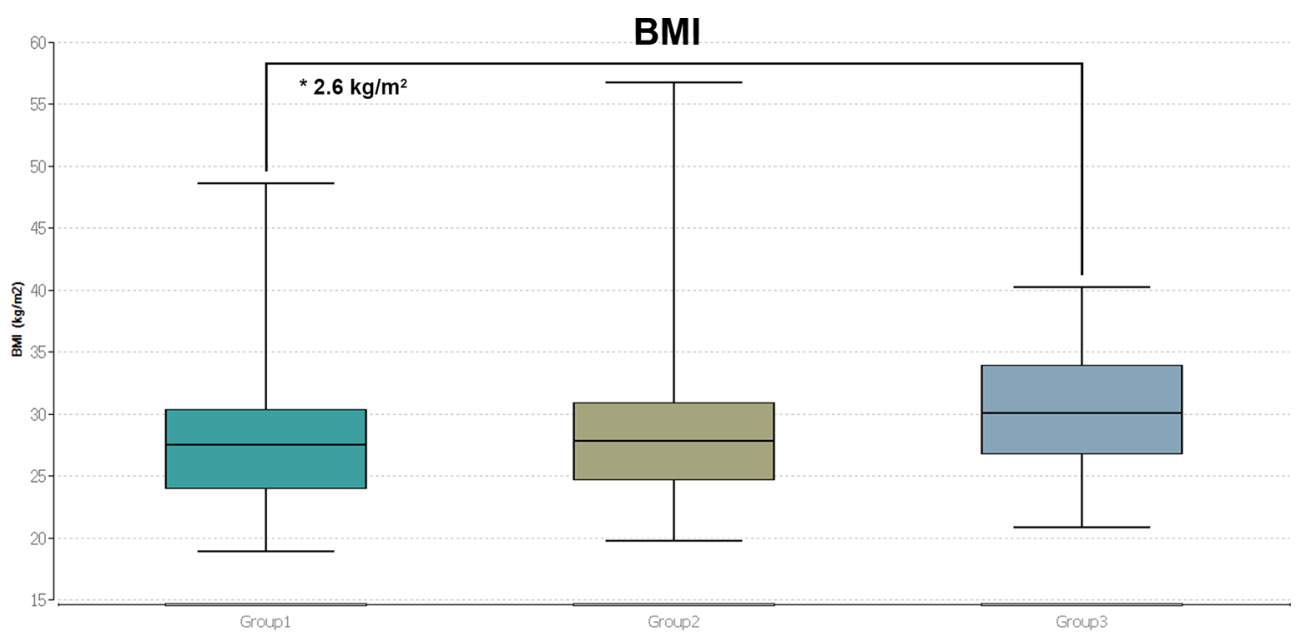

Figure 4 BMI distribution: group 1 (0-12 working years), group 2 (13-25 working years) and group 3 ( $>26$ working years). BMI, body mass index. 
continuous damage, we classified truck drivers according to their years of work.

Significant differences are associated in the frontal and sagittal sway with a longer professional life increasing by $22 \%(2.3 \mathrm{~mm})$ in sagittal and $15 \%(2.6 \mathrm{~mm})$ frontal in sway from group 2 (13-25 years of work) to group 3 (26 and more years of work) (figure 2a,b).

However, long-term truck driving does not result in a significant, unilateral, pathological redistribution of percentage load distribution of body weight.

The group comparison of BMI groups (WHO classification) shows that the increase of frontal $(4.2 \mathrm{~mm})$ and sagittal $(7 \mathrm{~mm})$ sway corresponds to the rise of the BMI between normal weight and obesity ${ }^{\circ} 2$ participants (figure 3a,b). Changes in the percentage weight distribution could not be recorded here.

There is a significant (steadily increasing) link between the number of years worked as a truck driver and an increase in BMI. Truck drivers have been found to be overweight for the most part, which was shown already by other authors. ${ }^{111327}$ Especially the sedentary lifestyle through long sitting hours in the driver's cabin and an unhealthy diet have to be mentioned as explanations for the high prevalence of obesity among truck drivers. ${ }^{24} 2528$

In total, less than a quarter of the examined truck drivers could be classified to be of normal weight $(23.6 \%)$ whereas more than a third of the studied truck drivers suffered from severe obesity (obesity ${ }^{\circ} 1-3$ (groups 3-5)) (37.2\%). In our study, the percentage value of overweight subjects is higher $(76.1 \%)$ than in other similar studies with $67 \%$ (including pre-obesity (group 2)). ${ }^{24}$

In addition to the number of working years, growing obesity with increasing working time can be seen as a factor influencing the increasing deflections of the frontal and sagittal sway of the COP. Age may be an additional factor which could explain our observations but must be analysed with a larger database.

Birtane and Tuna ${ }^{11}$ explained a ventral shift of the body's centre of gravity by abdominal fat. Since we have no indicator for the abdominal fat, the relevance of this factor could not be established. We did not find significant changes of the rearfoot-forefoot pressure distribution.

As proven in other studies, truck drivers often suffer from degenerative diseases of the locomotor system and diseases of the muscular-skeletal system. ${ }^{20}{ }^{21}$ The results of our study correspond to those of other authors, ${ }^{18}$ in which long periods of sitting encourage an increase of frontal and sagittal sway. Possible reasons why longterm truck driving does not affect the redistribution of the weight distribution has to be examined in further studies.

Comparing studies between truck drivers and the normal population have already shown ${ }^{23}$ that truck drivers more often suffer from back pain. This can be confirmed in our study. Almost $62 \%$ of the participating truck drivers indicate that they are suffering from back pain. Nevertheless, no objective differences between truck drivers with and without back pain could be found.

Consequently, back pain is not a factor influencing the postural sway. ${ }^{14}$ Obesity and lack of exercise and sportstwo favourable factors for the onset of back pain-are widely common in truck drivers. ${ }^{28}$ Future studies might examine this coherence more precisely.

Based on the findings, truck drivers might be offered individual health promotion offers. Fitness studios might be included in motorway service stations. Health insurance companies might offer incentives for the use of these fitness rooms. In addition, the driver's seat might be improved and the occurrence of back ache reduced by developing individualised seats, for example, by optimised suspension.

It can therefore be shown that obesity is prevalent among truck drivers. This also has an effect on postural sway, as there is an increase in the frontal and sagittal sway.

Moreover, it seems that working as a truck driver for several years and the long period of continuous upright sitting position disturbs the postural sway mechanisms, which results in an increase of sway. Other studies already stated the influence of obesity and long-term sitting on the postural control. ${ }^{1013}$

\section{CONCLUSION}

It can only be concluded that the frontal and sagittal sway of truck drivers is associated with long sitting, BMI and age. Significant objective effects of back pain on postural sway could not be proven. Measuring postural sway might serve as an early indicator of musculoskeletal dysfunction ${ }^{78}$ which may be improved by physical activity and/ or weight reduction. This study supports the findings of other studies which showed a coherence between musculoskeletal dysfunction and postural control.

Acknowledgements The authors thank the Daimler AG (Germany) for a donation to conduct this study. This article contains parts of the doctoral thesis of P. Troebs.

Contributors DO, PT, AL, EW, JN and DG made substantial contributions to the conception and design of the manuscript. DO, PT and AL made substantial contributions to the construction of the measurement protocol. D0 and PT has been involved in the statistical data analysis. All authors have read and approved the final manuscript.

Competing interests None declared.

Ethics approval This study was approved by the ethics board for research involving human subjects of the Goethe- University (134/14) in Frankfurt am Main, Germany.

Provenance and peer review Not commissioned; externally peer reviewed.

Data sharing statement For additional data see Supplementary Data.

Open Access This is an Open Access article distributed in accordance with the Creative Commons Attribution Non Commercial (CC BY-NC 4.0) license, which permits others to distribute, remix, adapt, build upon this work non-commercially, and license their derivative works on different terms, provided the original work is properly cited and the use is non-commercial. See: http://creativecommons.org/ licenses/by-nc/4.0/

(C) Article author(s) (or their employer(s) unless otherwise stated in the text of the article) 2017. All rights reserved. No commercial use is permitted unless otherwise expressly granted. 


\section{REFERENCES}

1. Comerford MJ, Mottram SL. Movement and stability dysfunctioncontemporary developments. Man Ther 2001;6:15-26.

2. Breithecker D. Der Rücken im Kontext der Gesamtkörperstatik. Haltung und Bewegung 1992;2:23-9.

3. Peterka RJ. Sensorimotor integration in human postural control. J Neurophysiol 2002;88:1097-118.

4. Peterka RJ, Loughlin PJ. Dynamic regulation of sensorimotor integration in human postural control. J Neurophysiol 2004;91:410-23.

5. Zajac FE, Neptune RR, Kautz SA. Biomechanics and muscle coordination of human walking. part I: introduction to concepts, power transfer, dynamics and simulations. Gait Posture 2002;16:215-32.

6. Ohlendorf D, Mickel C, Filmann N, et al. Standard values of the upper body posture and postural control: a study protocol. J Occup Med Toxicol 2016;11:34.

7. Buckley C, Galna B, Rochester L, et al. Attenuation of Upper Body Accelerations during Gait: piloting an Innovative Assessment Tool for Parkinson's Disease. Biomed Res Int 2015;2015:1-6.

8. Summa A, Vannozzi G, Bergamini E, et al. Multilevel Upper Body Movement Control during Gait in Children with Cerebral Palsy. PLoS One 2016;11:e0151792.

9. Comerford MJ, Mottram SL. Functional stability re-training: principles and strategies for managing mechanical dysfunction. Man Ther 2001;6:3-14.

10. Oullier O. Variability in Postural Coordination Dynamics. In: Davids K, ґBS, Newell KM, eds. Movement system variability. Champaign: human kinetics, 2006.

11. Birtane $M$, Tuna $H$. The evaluation of plantar pressure distribution in obese and non-obese adults. Clin Biomech 2004;19:1055-9.

12. Hills AP, Hennig EM, Byrne NM, et al. The biomechanics of adiposity-structural and functional limitations of obesity and implications for movement. Obes Rev 2002;3:35-43.

13. Colné P, Frelut ML, Pérès G, et al. Postural control in obese adolescents assessed by limits of stability and gait initiation. Gait Posture 2008;28:164-9.

14. Hue O, Simoneau M, Marcotte J, et al. Body weight is a strong predictor of postural stability. Gait Posture 2007;26:32-8.

15. Røgind $\mathrm{H}$, Lykkegaard JJ, Bliddal $\mathrm{H}$, et al. Postural sway in normal subjects aged $20-70$ years. Clin Physiol Funct Imaging 2003;23:171-6.
16. Szeto GP, Straker LM, O'Sullivan PB. A comparison of symptomatic and asymptomatic office workers performing monotonous keyboard work-1: neck and shoulder muscle recruitment patterns. Man Ther 2005;10:270-80.

17. Ellinghaus D, Steinbrecher J. Eine Untersuchung über die beziehungen zwischen Ikw- und Pkw-Fahrern. UNIROYALVerkehrsuntersuchung. Hannover: Continental AG, 2002.

18. Gawda P, Dmoszyńska-Graniczka M, Pawlak H, et al. Evaluation of influence of stretching therapy and ergonomic factors on postural control in patients with chronic non-specific low back pain. Ann Agric Environ Med 2015;22:142-6.

19. Birdsey J, Sieber WK, Chen GX, et al. National Survey of US LongHaul Truck driver Health and Injury: health behaviors. J Occup Environ Med 2015;57:210-6.

20. Layne DM, Rogers B, Randolph SA. Health and gender comparisons in the long-haul trucking industry: a pilot study. Aaohn $J$ 2009;57:405-13.

21. Michaelis M. Gesundheitsschutz und Gesundheitsförderung Von Berufskraftfahrern. Forschung Projekt F 2038. Dortmund, Berlin: Dresden: BAuA, 2008.

22. Nolle T. Mobile Berufe-Eine Untersuchung der Arbeitsbedingungen und der Ernährung im Hinblick auf die Gesundheit. Dortmund: Dissertation, 2005.

23. Anderson JE, Govada M, Steffen TK, et al. Obesity is associated with the future risk of heavy truck crashes among newly recruited commercial drivers. Accident Analysis \&amp; Prevention 2012;49:378-84.

24. Rosso GL, Perotto M, Feola M, et al. Investigating obesity among professional drivers: the high risk professional driver study. Am J Ind Med 2015;58:212-9.

25. Michaelis M, Rose U. Betriebliche Gesundheitsförderung für berufskraftfahrer. Prävention und Gesundheitsförderung 2011;6:40-7.

26. WHO. 2000. Obesity: Preventing and Managing the Global Epidemic. Report of a WHO Consultation: World Health Organization technical report series.

27. Schmucker U, Seifert C, Haasper G, et al. Unfälle, Erkrankungen und Verletzungen Im Güterkraftverkehr. Konsequenzen für die Medizinische Versorgung und prävention. Der Unfallchirurg 2012;115:1022-33.

28. Lange J, Groth J. Sicherheits- und gesundheitsschutzdefizite im speditionsgewerbe. Bremerhaven: Wirtschaftsverlag NW Verlag für neue Wissenschaft $\mathrm{GmbH}, 2005$. 